\title{
3D-printed CdTe QDs-based sensor for sensitive electrochemical detection of viral particles.
}

GARGULAK, M., DOCEKALOVA, M., KEPINSKA, M., SEHNAL, K., OFOMAJA, A.E., MILNEROWICZ, H., HOSNEDLOVA, B., STANKOVA, M., FERNANDEZ, C., HOAI, N.V., UHLIROVA, D., VASICKOVA, P., KIZEK, R.

(C) 20XX IEEE. Personal use of this material is permitted. Permission from IEEE must be obtained for all other uses, in any current or future media, including reprinting/republishing this material for advertising or promotional purposes, creating new collective works, for resale or redistribution to servers or lists, or reuse of any copyrighted component of this work in other works. 


\section{D-printed CdTe QDs-based sensor for sensitive electrochemical detection of viral particles}

\author{
Karel Sehnal \\ Department of Human Pharmacology and Toxicology, Faculty \\ of Pharmacy, University of Veterinary and Pharmaceutical \\ Sciences Brno, Palackeho 1946/1, 61242 Brno, \\ Brno, Czech Republic \\ karelsehnal15@gmail.com \\ Michael Gargulak \\ Department of Human Pharmacology and Toxicology, Faculty \\ of Pharmacy, University of Veterinary and Pharmaceutical \\ Sciences Brno, Palackeho 1946/1, 61242 Brno, \\ Brno, Czech Republic \\ michael.gargulak@seznam.cz \\ Bozena Hosnedlova \\ Department of Research and Development, Prevention Medicals, \\ Továrni 342, 742 13; \\ Studénka-Butovice, Czech Republic, \\ bozena.hosnedlova@post.cz \\ Nguyien Viet Hoai \\ Research Center for Environmental Monitoring and Modeling, \\ 144-Xuân Thủy Street - Cầu Giáy, Vietnam National University, \\ University of Science, \\ Ha Noi, Vietnam \\ nguyenviethoai@hus.edu.vn \\ Michaela Docekalova \\ Department of Research and Development, Prevention Medicals, \\ Továrni 342, 742 13; \\ Studénka-Butovice, Czech Republic, \\ docekalova@preventionmedicals.cz \\ Augustine Enakpodia Ofomaja \\ Biosorption and Wastewater Treatment Research Laboratory, \\ Department of Chemistry, Faculty of Applied and Computer \\ Sciences, Vaal University of Technology, P. Bag X021, \\ Vanderbijlpark, 1900, South Africa, \\ augustineo@vut.ac.za
}

\author{
Martina Stankova \\ Department of Research and Development, Prevention Medicals, \\ Továrni 342, 742 13; \\ Studénka-Butovice, Czech Republic, \\ stankova@preventionmedicals.cz \\ Dagmar Uhlirova \\ Department of Research and Development, Prevention Medicals, \\ Továrni 342, 742 13; \\ Studénka-Butovice, Czech Republic, \\ uhlirova@preventionmedicals.cz
}

\section{Marta Kepinska}

Department of Biomedical and Environmental Analyses, Faculty of Pharmacy with Division of Laboratory Medicine, Wroclaw Medical University, Borowska 211, 50-556 Wroclaw, Poland zalewska@gmail.cz

Halina Milnerowicz

Department of Biomedical and Environmental Analyses, Faculty of Pharmacy with Division of Laboratory Medicine, Wroclaw Medical University, Borowska 211, 50-556 Wroclaw, Poland zalewska@gmail.cz

Carlos Fernandez

School of Pharmacy and Life Sciences, Robert Gordon University, Garthdee Road, Aberdeen AB10 7QB,

Abeerdeen, United Kingdom

c.fernandez@rgu.ac.uk

Petra Vasickova

Department of Food and Feed Safety, Veterinary Research Institute, Hudcova 70, 62100 Brno, Brno, Czech Republic vasickova@vri.cz

Rene Kizek

Department of Food and Feed Safety, Veterinary Research Institute, Hudcova 70, 62100 Brno,

Brno, Czech Republic

kizek@sci.muni.cz

\begin{abstract}
Preventing the spread of dangerous viral diseases such as flu, Ebola virus disease or HIV disease requires rapid and effective diagnostic approaches to detect these diseases at an early stage. Quantum dots (QDs) are nanocrystals that exhibit a variety of unique properties and are suitable for biomolecule labelling due to their high stability, ease of preparation, and biocompatibility. Modified QDs can be used to label nucleic acids or antibodies. Green synthesis method of QDs provides a platform for preparation of unique materials with new chemical or physical properties as compared to the original material. In this work, CdTe QDs were produced in the presence of plant extract which acted as a modifying agent. The Zea mays extract was added during the CdTe QDs synthesis at different time intervals and CdTe QDs of a wide range of colors were obtained. The stability of the prepared QDs, including their application onto paper, was evaluated. The QDs were observed to show a very good electrochemical response for sensor application and were therefore used to
\end{abstract}

label virus-specific antibody. The entire procedure was miniaturized and the viral particles were analyzed in a 3Dprinted chip.

Keywords- QDs, green synthesis, viral infection, CdTe, sensors, electrochemistry, antibody

\section{INTRODUCTION}

The rapid spread of serious viral diseases such as flu, Ebola virus disease or HIV disease requires appropriate tools for proper epidemiological measures. At the beginning of the 21 st century, ASFV virus began to spread pandemically. ASFV (African Swine Fever Virus) is a DNA virus belonging to the Asfivirus genus and the Asfarviridae family found in the blood, body fluids, internal organs, and all secretions and excreta of the host. The virus can be excreted 1-2 days before clinical symptoms (maximum is at the time 
of septicemia) [1]. ASFV is extremely pathogenic, mortality of infected animals of the Suidae family reaches up to $100 \%$. From epidemiological data, it is obvious that only $3-5 \%$ of animals can survive the infection [2]. These facts point to an extremely dangerous hemorrhagic virus uniquely belonging to the biosafety level 4 (BSL4) category. Diagnosis and new onsite health diagnostics using biosensing technology can bring significant economic benefits with a clear use to overcome similar epidemics in humans [3]. Such sensors can be used for early and rapid detection of selected viruses performed even by non-specialized personnel. The proposed technology is capable of detecting pathogens in different types of biological samples such as oral fluids, faeces, blood, and nasal swabs [1, 2]. Design and construction of sensors/biosensors require very sensitive detection as well as a recognition part. The sensor/biosensor recognition part can be designed using green synthesis, which provides new unique properties [3]. For this purpose, whole plants, organs or tissues are often used. One of the most sensitive method for analyte detection is fluorescence or electrochemical detection technique. Quantum dots (QDs) nanoparticlelabeled molecules can be used to design new types of sensors/biosensors [4-7]. Quantum dots are nanocrystals of sizes from 2 to $10 \mathrm{~nm}$ that absorb a wide spectrum of light and show fluorescence under UV light [8]. Such nanocrystals are formed by the action of reductants in thermal synthesis, where chemical reducing agents can be replaced by mixtures (bio-extracts) [9]. As a result, nanoparticles which have their surfaces modified by biomolecules from the extract, are formed. With these molecules, we can label a suitable recognition element of the biosensor (usually an antibody). Based on available information on limits of known biosensors, viral particle detection limits are in the range of fM units [10]. The aim of this work was to prepare CdTe QDs through green synthetic route, to label a suitable antibody with these nanoparticles and to apply the prepared conjugate to the detection of viral particles by the electrochemical technique using the 3D-printed chip platform.

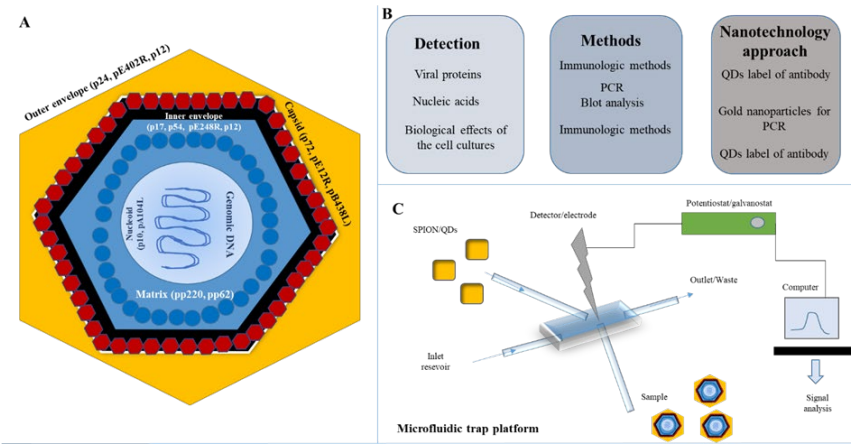

Fig. 1. Schematic illustration of the localization of different ASFV structural proteins. Adapted from Salas and Lyra [4] (A). Selected possible approaches for identifying the presence of ASFV virus with respect to nanotechnology options. Labeling of antibodies or selected proteins with quantum dots, and using gold nanoparticles to boost nucleic acid amplification by PCR (B). Design of a microfluidic platform prepared by $3 \mathrm{D}$ printing. SPION/QDs and viral sample are injected into the reactor. Detection is done electrochemically. The resulting signal is collected and analyzed by computer $(\mathrm{C})$.

\section{MATERIAL AND METHODS}

\section{A. Chemicals}

All chemicals used in this study such as $\mathrm{Cd}\left(\mathrm{CH}_{3} \mathrm{COO}\right)_{2}$. $2 \mathrm{H}_{2} \mathrm{O}, \mathrm{Na}_{2} \mathrm{TeO}_{3}$, mercaptosuccinic acid (MSA), Trizma base and $\mathrm{HCl}$ were purchased from Sigma-Aldrich (St. Louis, $\mathrm{MO}$, USA), in ACS purity. Propanol and NaBH4 was purchased from Merck (Darmstadt, Germany), and 25\% aqueous $\mathrm{NH} 4 \mathrm{OH}$ was purchased from Lach-Ner s.r.o. (Neratovice, Czech Republic). All chemicals that we used for gel electrophoresis were purchased from VWR (Germany). All plastic materials used (tubes, tips) in this study were purchased from Eppendorf (Hamburg, Germany). Deionised water was prepared by using the reverse osmosis equipment Aqual 25 (Brno, Czech Republic), and was further purified by using an ELGA apparatus equipped with a UV lamp (Lane End, United Kingdom). The resistance was $18 \mathrm{M} \Omega$ and the $\mathrm{pH}$ was measured using the $\mathrm{pH}$ meter (WTW).Silver nitrate, methanol, $\mathrm{NaCl}$ and other chemicals were purchased from Merck (USA) at a purity $>99 \%$. Tryptone and yeast extract from Duchefa Biochemie (Germany) were purchased for the cultivation of microorganisms.

\section{B. Instruments}

Absorption and fluorescence spectra were obtained using the Tecan Infinite 200 PRO Multifunctional Reader (TECAN, Switzerland). For absorption spectra, the wavelength was in the range from 400 to $800 \mathrm{~nm}$. For fluorescence spectra, there was an excitation wavelength of $250 \mathrm{~nm}$ and an emission wavelength in the range from 350 to $800 \mathrm{~nm}$. The optical properties of nanoparticles were studied by spectral analysis. The absorbance spectra of nanoparticles were recorded within the range of 400 to $800 \mathrm{~nm}$ using a UV-3100PC UV-VIS spectrophotometer (VWR, Germany).

\section{CdTe quantum dots synthesisration of AgNPs by green synthesis}

The preparation of CdTe quantum dots (QDs) was performed as follows: $10 \mathrm{~mL}$ of solution $\mathrm{Cd}\left(\mathrm{CH}_{3} \mathrm{COO}\right)_{2}$ $2 \mathrm{H}_{2} \mathrm{O}(0.02 \mathrm{M}), 76 \mathrm{~mL}$ of $\mathrm{H}_{2} \mathrm{O}, 1 \mathrm{~mL}$ of MSA solution $(0.4$ $\mathrm{M}), 5 \mathrm{~mL}$ of $\mathrm{Na}_{2} \mathrm{TeO}_{3}(0.02 \mathrm{M})$, and $40 \mathrm{mg}$ of $\mathrm{NaBH}_{4}$ were stirred with a magnetic stirrer (VMS-C4, VWR International Ltd., Darmstadt, Germany) for at least two hours until bubbling stopped. Subsequently, the volume was adjusted to $100 \mathrm{~mL}$. Then $2 \mathrm{~mL}$ of the prepared solution was pipetted into the glass vials (Sigma Aldrich, St. Louis, MO, USA) with a white cap (Anton Paar, Graz, Austria) and a Teflon cap (Anton Paar, Graz, Austria). The vial containing the mixture was placed in a microwave, which was set to a power of $300 \mathrm{~W}$, and the heating took place for 2 minutes for green QDs, 4 minutes for yellow QDs, 6 minutes for orange QDs, and 8 minutes for red QDs. The final concentration of QDs was $2 \mathrm{mM}$.

\section{Surface morphology of the nanoparticles}

Surface morphology of the nanoparticles was investigated with field emission scanning electron microscopy (FESEM) using operating voltage of $10 \mathrm{kV}$ in the SEM (Zeiss) instrument. Surface charging effect was minimized by coating the samples with gold on copper stubs with a coating instrument. Transmission electron microscope (TEM) and higher resolution TEM (JEOL) were determined on a copper stub with carbon glue and coated with gold 
before analysis. The samples for TEM and HRTEM were placed in vials containing absolute ethanol and ultrasonicated for $10 \mathrm{~min}$. thereafter, holey/lacey carbon grids $(10 \mu \mathrm{m})$ were dipped into the vials containing the ultrasonicated samples and dried before microstructural determination.

\section{E. Electrochemical determination of cadmium ions}

Determination of $\mathrm{Cd}^{2+}$ by difference pulse voltammetry (DPV) was performed at 663 VA Stand (Metrohm, Switzerland). A standard cell with three electrodes was used, and a hanging mercury drop electrode (HMDE) with a drop area of $0.4 \mathrm{~mm}^{2}$ was employed as the working electrode. An $\mathrm{Ag} / \mathrm{AgCl} / 3 \mathrm{M} \mathrm{KCl}$ electrode acted as the reference and a carbon electrode was auxiliary. For data processing, VA database software by Metrohm was employed. The analysed samples were deoxygenated prior to measurements by purging with argon $(99.999 \%)$. Acetate buffer (0.2 M sodium acetate and $0.2 \mathrm{M}$ acetic acid, $\mathrm{pH}=5$ ) was used as a supporting electrolyte. The parameters of the measurement were as follows: initial potential $-1.2 \mathrm{~V}$, end potential $0 \mathrm{~V}$, deoxygenating with argon $120 \mathrm{~s}$, accumulation time $120 \mathrm{~s}$, step potential $5 \mathrm{mV}$, modulation amplitude $25 \mathrm{mV}$, the volume of injected sample: $50 \mu \mathrm{L}$ and volume of measurement cell $10 \mathrm{~mL}$. The samples, the electrolyte, and the measuring vessel were thermostated using the JULABO200 circulation pump (Germany). The temperature was set to $20^{\circ} \mathrm{C}$ for all measurements.

\section{F. SDS/PAGE analysis and $3 D$ printing}

The VWR E 0322-VWR-230V electrophoretic source and the mini-horizontal electrophoretic system (VWR, Germany) were used for the analysis. The gels were prepared from $30 \%(\mathrm{~m} / \mathrm{V})$ acrylamide stock solution with $1 \%(\mathrm{~m} / \mathrm{V})$ bisacrylamide. The composition of the running gel was as follows: $15 \%(\mathrm{~m} / \mathrm{V})$ acrylamide, $0.5 \%(\mathrm{~m} / \mathrm{V})$ bisacrylamide, $0.1 \%$ SDS (m/V), 0.083\% TEMED (V/V), 0.05\% APS $(\mathrm{m} / \mathrm{V}), 0.376 \mathrm{M}$ Tris $/ \mathrm{HCl}, \mathrm{pH} 8.8$. The composition of the stacking gel was as follows: $4.5 \%$ acrylamide $(\mathrm{m} / \mathrm{V}), 0.15 \%$ bisacrylamide $(\mathrm{m} / \mathrm{V}), 0.1 \%$ SDS $(\mathrm{m} / \mathrm{V}), 0.1 \%$ TEMED $(\mathrm{V} / \mathrm{V}), 0.05 \%$ APS $(\mathrm{m} / \mathrm{V}), 0.125 \mathrm{M}$ Tris/HCl, $\mathrm{pH}$ 6.8. The QDs tested were diluted 2:1 with $30 \%$ glycerol in the test tube. The gel wells were dosed with $50 \mu \mathrm{L}$ of the thus diluted QDs. The conditions for electrophoresis were $100 \mathrm{~V}$ for 1.5 hours in running buffer $(24 \mathrm{mM}$ Tris, $0.2 \mathrm{M}$ glycine, and 3 $\mathrm{mM}$ SDS). After the electrophoresis was complete, the gel was removed and transferred to a dark room where it was illuminated by a UV lamp, and photographic documentation (Canon, 12Mpx) was performed. The 3D object was modeled using the Sketchup 2016 software. 3D printer Profi3DPrinter (company - 3DFactories, technology - FDM) was employed for 3D printing. A white ABS (acrylonitrile butadiene styrene) $3 \mathrm{D}$ printer filament was used. The filament was melted in a print head at $230{ }^{\circ} \mathrm{C}$ and then it was applied by a nozzle $(\varnothing 0.5 \mathrm{~mm})$ in thin layers onto a heated plate $\left(80^{\circ} \mathrm{C}\right)$.

\section{G. Statistical analysis of data}

Experimental work was performed in at least three independent experiments. Each sample in the experiments was analysed at least five times. The obtained data presented in this paper are the average values. No experimental points were excluded from the proposed experimental study. All the obtained data were stored in the Qinslab database (Prevention Medicals, CR). If possible, data were processed and evaluated mathematically and statistically in the Qinslab database. The results were expressed as mean \pm standard deviation (SD). Photos were processed by the ColorTest program, which assigns an intensity to the individual pixels of the studied image in a given color area [11]. For preparing the publication, the data were processed using MICROSOFT software (USA).

\section{RESUlTS AND DISCUSSION}

Viral nanoparticles consist of a viral envelope that is one of the main targets of the biosensor recognition element (Fig. 1A). Technically and technologically, viruses can be recognized by various methodological approaches, as summarized in Fig. 1B. In our experiment, we decided to use a combination of the flow analysis in a 3D-printed chip and high-sensitivity electrochemical detection. For analysis, a 3D printing microfluidic trap platform was designed. In the concept, a reaction reservoir was designed into which the sample input and detection system consisting of QDs and a printed electrode were introduced. The system was then connected to a suitable portable potentiostat with the evaluation unit (Fig. 1C). The 3D chip printing technology was optimized (print speed, number of layers, melting temperature). The prepared chip was tested for its stability. Stability was very good for temperature range from 10 to 80 ${ }^{\circ} \mathrm{C}$; mobile phase flow was $10-500 \mu \mathrm{L} / \mathrm{s}$; chemical reagents $0.1 \mathrm{M} \mathrm{NaOH}, 0.1 \mathrm{M} \mathrm{HCl}$, and $0.2 \mathrm{M}$ phosphate buffer were used. The sample and detection molecules were injected manually into the chip with a syringe $(10 \mu \mathrm{L})$. The mobile phase flow (0.2 M phosphate buffer, $\mathrm{pH} 7$ ) was $100 \mu \mathrm{L} / \mathrm{min}$ for most experiments. For the green synthesis of QDs, maize was used, which grows very well in hydroponic conditions. Seeds of maize (of Silen variety) were germinated and after 5 days, plants of the same height and root system were selected. Plants were transferred to the hydroponic growth system with only aerated distilled water with a different concentration of cadmium $\left(\mathrm{Cd}^{2+}\right)$ ions. It is known that $\mathrm{Cd}^{2+}$ reduce the activity of antioxidant enzymes and thus increase cell damage [12].

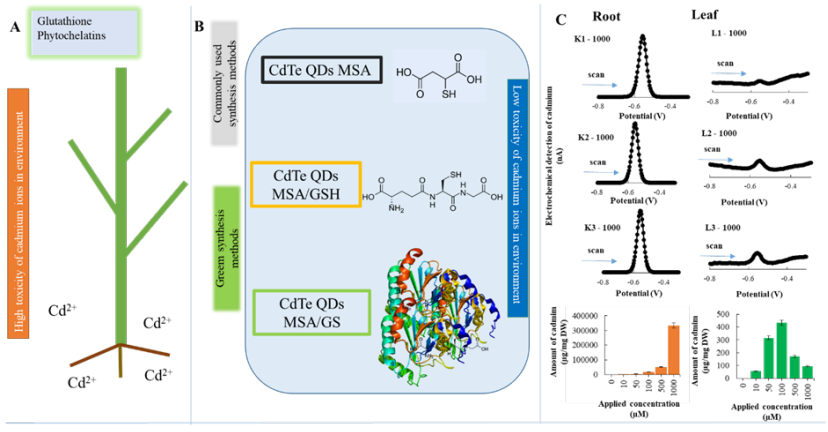

Fig. 2. Heavy metal ions are present in the environment often in very high concentrations, however, plants have developed a variety of defence mechanisms against heavy metal toxicity. The most important is the synthesis of thiol compounds (glutathione, phytochelatins). These compounds immobilize and significantly reduce the toxicity of heavy metal ions (A). The commonly used synthesis of QDs results from an acid surface modification (MSA). Biologically important molecules such as GSH can also be used to modify the surface. Plants that produce an increased amount of thiol compounds are a source of interesting molecules for surface modification of nanoparticles. Biologically modified nanoparticles are less toxic and can thus be a suitable basis for labeling in biodetection (B). For the synthesis of 
CdTe QDs, maize extracts were obtained from plants cultivated for 11 days in hydroponic conditions with applied cadmium ions (1 mM). Typical DP voltammograms of cadmium ions in mineralizates, $\mathrm{K}$ root, $\mathrm{L}$ - leaf. The total average amount of cadmium in the roots and leaves of plants exposed to $0,10,50,100,500$ and $1000 \mu \mathrm{M} \mathrm{Cd}^{2+}(\mathbf{C})$. suppress the formation of ATP and enzymes, prevent photosynthesis and cellular respiration $[12,13]$. It is known that organisms on Earth protect themselves from heavy metal ions by their binding to thiol compounds (glutathione, phytochelatins, metallothioneins) $[14,15]$ (Fig. 2A). These unique properties were subsequently used for the synthesis. Plants were harvested after 11 days of cultivation and aqueous extracts were prepared (homogenization in a mortar for $30 \mathrm{~min}$, sonication for $15 \mathrm{~min}$, and vortexing for $5 \mathrm{~min}$ ). The amount of cadmium was analyzed electrochemically. Typical voltammograms of cadmium in roots and leaves are in Fig. 2C. The amount of detected cadmium increased depending on the concentration of $\mathrm{Cd}^{2+}$ ions applied. The highest values in the roots were observed at the highest applied concentration of $\mathrm{Cd}^{2+}$ ions. In leaves, the cadmium concentration was highest at an applied concentration of 100 $\mu \mathrm{M}$. A basic solution for the synthesis of CdTe QDs was prepared. Mercaptosuccinic acid (MSA), and biological agents (bio) such as glutathione (GSH), leaf extract or root extract were used for the reduction. Thermal microwave synthesis was then performed (at $350 \mathrm{~W}$ for $1-5 \mathrm{~min}$ ). Green, yellow, orange, and red QDs were obtained in the experiment (Fig. 2B). In Fig. 3Aa, there is a photograph of acquired QDs after exposure to UV radiation $(360 \mathrm{~nm})$. To verify the stability of the prepared QDs CdTe/MSA/bio, they were printed on paper (Fig. 3Ab); the individual samples were applied at a sequentially given sample volume from a total volume of $4 \mu \mathrm{L}$, the print speed was $10 \mathrm{~nL} / \mathrm{s}$, the length of the printed strip was $5 \mathrm{~mm}$. After deposition of the samples, the paper was irradiated with UV light (365 and $230 \mathrm{~nm}$ ). The stability of the QDs thus prepared is more than 1 year (a decrease in fluorescence to a maximum of $10 \%$ ). A typical XRD spectrum of prepared QDs - the signals of both the CdTe material used and the biological component $-\mathrm{C}, \mathrm{N}$, $\mathrm{O}, \mathrm{S}$ elements - is shown in Fig. 3Ac. In Fig. 3B, there are SEM microphotographs of green, yellow, orange, and red CdTe QDs. A proposed scheme of the detection part of the prepared biosensor for detecting viral particles is shown in Fig. 3C. The sensor is based on a magnetic particle (SPION) that can be anchored to the magnet.
In plants, $\mathrm{Cd}^{2+}$ (deposited mainly in roots and leaves)
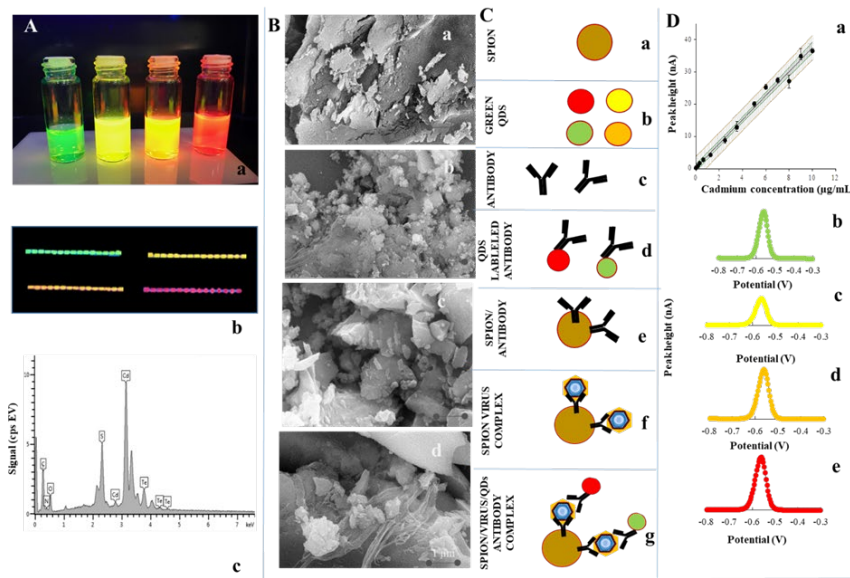

Fig. 3. (A) Typical green CdTe after microwave synthesis 1, 2, 3 min, 300 $\mathrm{W}$, the photograph made at lightening $-5 \mathrm{~W}, 320 \mathrm{~nm}$ (a); QDs deposited on paper and visualized at $260 \mathrm{~nm}$ (b); Typical XRD spectrum of CdTe QDs (c). (B) Typical SEM images of green (a), yellow (b), orange (c) and, red (d) QDs, EHT $20 \mathrm{kV}$, WD $8.5 \mathrm{~mm}$, Mag 10,000. (C) The proposed method for virus detection, the use of SPION particles for easy purification of viral nanoparticles (a), green QDs are used to label antibodies (b), suitable antibodies for capturing viral particle (c), antibodies modified by suitable QDs (d) SPION particles are modified by a antibody with a high affinity to the viral capsid (e), SPION/VIRUS complex (f), SPION/VIRUS/QDS/ANTIBODY complex (g). The complex formed was analyzed electrochemically. (D) A typical DPV dependence on the concentration of cadmium ions (a) and the response of green (b), yellow (c), orange (d), and red (e) QDs.

SPION is modified by the EDC/NHS polymer and an antibody with high affinity to the surface structures of the virus is anchored on its surface. The second antibody, which is labeled with CdTe QDs, was used in the system. The viral particle was bound to SPION and then the binding of the labeled antibody to the virus occured. The CdTe QDs were subsequently electrochemically determined on the carbon electrode. All QDs used have been found to provide very good electrochemical signals (typical green, yellow, orange, and red QDs signals are in Fig. 3D). The CdTe QDs calibration relationship was linear $(r=0.999$, LOD $=0.5$ $\mathrm{nM}$ ). The proposed detection system was used to analyse viral particles with very good repeatability (RSD up to $10 \%$ ).

\section{CONCLUSION}

QDs were prepared by plant-based green synthesis. Subsequently, they were used to construct the biosensor. The specific antibody for the recognition of the virus molecules was determined electrochemically. The proposed concept was used for designing a 3D-printed chip.

\section{Acknowledgment}

The work was realized thanks to the project QK1920113 and international collaboration project of The European Technology Platform for Nanomedicine.

\section{REFERENCES}

The work was realized thanks to the project QK1920113.
C. Montagnese et al., "A Diagnostic Device for InSitu Detection of Swine Viral Diseases: The SWINOSTICS Project," Sensors, vol. 19, no. 2, p. 407, 2019. 
[2] S. Murai et al., "A FRET biosensor for necroptosis uncovers two different modes of the release of DAMPs," (in English), Nature Communications, Article vol. 9, p. 17, Oct 2018, Art. no. 4457.

[3] W. Leitner, "Green chemistry - Frontiers in benign chemical syntheses and processes," (in English), Science, Book Review vol. 284, no. 5421, pp. 1780-1781, Jun 1999.

[4] E. Oh et al., "Meta-analysis of cellular toxicity for cadmium-containing quantum dots," (in English), Nature Nanotechnology, Article vol. 11, no. 5, pp. 479-+, May 2016.

[5] F. Nasrin et al., "Single-step detection of norovirus tuning localized surface plasmon resonanceinduced optical signal between gold nanoparticles and quantum dots," (in English), Biosensors \& Bioelectronics, Article vol. 122, pp. 16-24, Dec 2018.

[6] N. A. S. Omar, Y. W. Fen, J. Abdullah, N. A. A. Anas, N. S. M. Ramdzan, and M. A. Mahdi, "Optical and structural properties of cadmium sulphide quantum dots based thin films as potential sensing material for dengue virus E-protein," (in English), Results in Physics, Article vol. 11, pp. 734-739, Dec 2018.

[7] C. J. Bai et al., "Aptamer selection and application in multivalent binding-based electrical impedance detection of inactivated H1N1 virus," (in English), Biosensors \& Bioelectronics, Article vol. 110, pp. 162-167, Jul 2018.

[8] J. H. Duarte, "DNA cages target quantum dots," (in English), Nature Biotechnology, Editorial Material vol. 34 , no. 10 , pp. 1036-1036, Oct 2016.
[9] B. Yuan, T. K. Egner, V. Venditti, and L. Cademartiri, "Sustainable scalable synthesis of sulfide nanocrystals at low cost with an ionic liquid sulfur precursor," (in English), Nature Communications, Article vol. 9, p. 7, Oct 2018, Art. no. 4078.

[10] A. D. Chowdhury et al., "Femtomolar Detection of Dengue Virus DNA with Serotype Identification Ability," (in English), Analytical Chemistry, Article vol. 90, no. 21, pp. 12464-12474, Nov 2018.

[11] D. Uhlirova, M. Docekalova, M. Stankova, L. Melichar, J. Ruzicka, and R. Kizek, "A diagnostic strip for determining the amount of sarcosine, creatinine and hydrogen peroxide in a biological or environmental sample," PUV Czech Republic, vol. 30831, no. 2017-33695, 2017.

[12] A. Winiarska-Mieczan, "Protective effect of tea against lead and cadmium-induced oxidative stressa review," (in English), Biometals, Review vol. 31, no. 6, pp. 909-926, Dec 2018.

[13] C. T. McMurray and J. A. Tainer, "Cancer, cadmium and genome integrity," (in English), Nature Genetics, Editorial Material vol. 34, no. 3, pp. 239-241, Jul 2003.

[14] M. Rizwan et al., "Cadmium phytoremediation potential of Brassica crop species: A review," (in English), Science of the Total Environment, Review vol. 631-632, pp. 1175-1191, Aug 2018.

[15] J. E. Gawel, B. A. Ahner, A. J. Friedland, and F. M. M. Morel, "Role for heavy metals in forest decline indicated by phytochelatin measurements," (in English), Nature, Article vol. 381, no. 6577, pp. 64-65, May 1996. 